\title{
How University Students Managed Conflictual Talk in Small- Group Text Discussion
}

\author{
Feng-ming Chi \\ National Chung Cheng University, Taiwan \\ E-mail: folfmc@ccu.edu.tw
}

Received: 27-02-2016

Accepted: 06-05-2016

Advance Access Published: May 2016

Published: 01-07-2016

doi:10.7575/aiac.ijalel.v.5n.4p.154

URL: http://dx.doi.org/10.7575/aiac.ijalel.v.5n.4p.154

The article is financially supported by National Science Council, Taiwan (NSC 102-2410-H-I94-036-MY2).

\begin{abstract}
The aim of this article was to investigate how 10 groups of Taiwanese university students managed conflictual talk via two text discussions, and how they perceived such talk as a social act of reading. Data sources included each group's text discussions and an oral interview with each participant. Three holistic, detailed, and selective approaches were used to glean the meaning of the data; as a result, five aspects of conflictual talk, namely, collaboration, reflexivity, humor, alteration, and collision were generated for discussion. The findings revealed that conflictual talk provided multiple opportunities for participants to carry out meaning co-construction with their peers; participants not only clarified, elaborated, and challenged one another's ideas, but also had to listen attentively to one another and direct the discussion themselves. However, if any group members showed no interest in negotiating meaning with their peers, conflictual talk may lead to confrontations. The pedagogical implications of this work are also addressed.
\end{abstract}

Keywords: English language learning, text discussion, conflictural talk, collaboration, reflexivity, collision

\section{Introduction}

In recent years, following an increased emphasis on students as meaning makers in learning English-as-a-FirstLanguage (L1) and English-as-a-Second-Language (ESL), many researchers in Taiwan have suggested that studentcentered tasks be applied to the contexts of English taught as a Foreign Language (EFL). One of the preferred activities to achieve this is small-group text discussions, since they provides students with opportunities to share what they have read, to hear the opinions of their peers, and to teach and be taught by fellow students (Berne \& Clark, 2006; McElvain, 2010). However, such discussions do not run smoothly all the time, since conflicts may emerge if the students encounter alternate interpretations, or discourses that force them to reconsider their own interpretations of a text. Short and Burke (1996) viewed conflict in text discussion as a driving force to help students move ahead, encouraging them not to get bogged down with textual difficulties and confusions which may make them lose sight of the overall picture of the text being read. For Short and Burke (1996), social conflict lays the groundwork for exploration of the focal text from different perspectives. Echoing this positive view, Almasi (1995) and Almasi and Gambrell (1997) applied the concept of sociocognitive conflicts to compare the conflicts generated from teacher- and peer-led discussions. One of Almasi's major findings was that when students were positioned to try their own words and thoughts, this resulted in more extended and elaborate mental representations and higher level analytical thinking and problem solving. For Almasi, peer-led discussions with sociocognitive conflicts during small-group discussions provide students with an opportunity to utilize various thought processes, as well as to monitor and update their interpretations. Taking a cross-cultural perspective, Carson and Nelson (1994, 1996) investigated how ESL students from different cultural backgrounds interacted with their peers in their own writing. They concluded that Asian students, including Taiwanese ones, tended to keep their disagreements to themselves, because a direct statement is likely to create conflict and tension within the group, an occurrence they wish to avoid. A more recent study was undertaken by Chi (2012), who used three patterns of interactive talk, collaborative, complementary, and conflicting, to examine how Taiwanese university students shared, negotiated, and challenged meaning in small-group discussions. She found that social conflicts function as sources for further inquiry. However, similar in Carson and Nelson's studies, some students in Author's research worked hard to minimize group conflict, and this had adverse affects on their learning. As highlighted by Almasi and Author, social conflicts in small-group text discussions are not like a brick wall that students run up against or bruise themselves on when they kick at. Instead, social conflicts provide groups with opportunities to seek solutions, overcome ambiguities, or resolve confusions, by searching for alternative ways to modify, explain, elaborate, reorganize, or even reconceptualize the text under discussion (Purky, 2008). Author further suggested that future studies need more thorough investigations of how students manage social conflicts and under what conditions such actions could enhance or impair their learning. Therefore, by drawing data from a large research-based project, this article examines how 10 groups of Taiwanese EFL university students engaged in conflictual talk as socially situated inquiry in their attempts to comprehend and interpret two stories in English, and how they perceived such talk as a social act of reading in the process of small-group text discussions. 


\section{Method}

\subsection{Research Setting and Participants}

The setting for this study was a national university, with a campus of around 12,000 students, located in central Taiwan. 30 Taiwanese EFL university students, four males and 26 females volunteered to take part in this study. I first sent invitation letters to possible participants, indicating the purpose of this study and how much time they would be expected to spend on the research task. The students were also encouraged to form groups of three by themselves. 42 students responded to my letter, and I then conducted oral interviews to recruit appropriate participants. More specifically, the participants were required to have no difficulty in discussing the two short stories used in this project, and thus their oral proficiency in English had to be at a level that allowed them to verbalize their thoughts without any difficulties. As a result, 30 students were evaluated as "capable of expressing ideas in English", and they were all sophomore or junior students majoring in English, ranging from intermediate to high-intermedaite levels of English proficiency. Many of them had taken at least one course with me before, and were willing to participate in this study mostly because of encouragement from myself or their peers. The participants were all classmates and/or roommates, and so were very familiar with one another before participating in the study. In general, each participant had been exposed to at least six years of high-school English, taught mainly by the grammar-translation method, and at least one year of university-level English.

\subsection{Texts for Discussions}

Two stories with medical themes, 'The Man Who Fell Out of Bed' and 'Yes, Father-Sister,' were selected and evaluated by two EFL instructors and student volunteers in the pilot study as the most interesting and meaningful texts for discussion purposes. Both stories were taken from Oliver Sacks' The Man Who Mistook His Wife for a Hat (1985), and are on similar themes, the struggles between a patient and doctor. 'The Man Who Fell out of Bed' presents a patient trying to deal with the loss of his leg, whereas 'Yes, Father-Sister' describes a patient (Mrs. B) whose world has been stripped of feeling and meaning due to the equalization, a neurological problem which means that she is not able to recognize the doctor as a whole person, but instead as part of a father and part of a sister.

\subsection{Data Collection and Analysis}

Each group of participants was first asked to read 'The Man Who Fell out of Bed' (Story One). When each of them finished reading the story individually, the whole group was then asked to discuss it. The groups were informed that they could talk about any aspects of the story and spend as much time as they wished, but that they should use English as the only medium for their discussions. After finishing their discussion of Story One, they were asked to continue with 'Yes, Father-Sister' (Story Two), and the same procedures were followed as for the first story. Semi-structured oral interviews were then used to shed more light on how the participants perceived the small-group text discussion as a social act of reading. Each participant was interviewed individually, with each interview generally lasting 8-10 minutes, and the participants were free to use either English and/or Mandarin in their responses. Both text discussions and interview data were audio-taped, and all the data were transcribed verbatim by two research assistants.

Three holistic, detailed and selective approaches were applied to glean the meaning of the text discussion data (van Manen, 1990). That is, initially I highlighted and identified portions of the data relevant to the conflictual talk, referring to the arguments, disagreements or even confrontations in the processes of discussions. More specifically, conflictual talk as an exchange strategy usually started with discourse markers such as "I don't think ...," "I don't quite agree..." or "No....", and usually ended with a consensus or an agreement, or generated another direction or topic for discussion. For the detailed approach, the relevant conflictual talk was then classified, organized, and finally moved together as an aspect. As a result, five aspects, collaboration, reflection, humor, alteration, and collision emerged from the data analysis, each revealing a different dimension of how conflictual talk was managed by these participants. The selective approach was used to look for key events as examples that were prevalent and/or significant for further in-depth discussions. I then narrowed down to focus on data comparisons for similar and different situations that emerged from the process of selection. An event usually reflects a complete central topic with several coherent ideas or points, which can be described based on contextual analysis for further use by the researcher (Bloome et al., 2008). Table 1 first presents an example to illustrate how the three approaches applied to code, classify and select the text discussion data, and this is followed by a detailed illustration of each aspect of conflictual talk as social shared inquiry in the process of two text discussions.

Table 1. A Sample of Data Analysis

\begin{tabular}{|c|c|c|c|}
\hline Line/Speaker/Data & Holistic & Detailed & Selective \\
\hline $\begin{array}{l}01 \text { Sue: Well, I don't quite agree that she } \\
02 \text { is a nut. We think the titles are important, } \\
03 \text { doctor, nurse, patients, but not to Mrs. B. } \\
04 \text { Mina: But why she sees the doctor as a } \\
05 \text { father and as a sister? Is she a \{fun-z\}. } \\
06 \text { Claire: If Mrs. B is a }\{\text { fun-z\}, she can't } \\
07 \text { tell the differences between a male and } \\
08 \text { a female, right? }\end{array}$ & $\begin{array}{c}\text { conflictural } \\
\text { (liens 01-08) }\end{array}$ & $\begin{array}{l}\text { collaboration } \\
\text { (lines 01-29) }\end{array}$ & $\begin{array}{l}\text { This example is } \\
\text { chosen due to its } \\
\text { two main points } \\
\text { on discussing why } \\
\text { Mrs. B sees the } \\
\text { doctor with } \\
\text { different titles as } \\
\text { father and as a } \\
\text { sister, and also on } \\
\text { whether Mrs. B is } \\
\text { insane or not. }\end{array}$ \\
\hline
\end{tabular}


09 Sue: I don't think she is a fun-z\}.

10 She is just de-desouled.

11 Mina: De-soul? No soul, like a ghost.

12 Claire: Well, something means nothing;

13 right is left and left is right; to be or not 14 to be; to have or not to have; -

15 Mina: Claire, you are like a female

16 Shakespea-rian. Haaa!

17 Sue: Like Lau-Chuang.

(Two philosophers in Ancient China)

18 Claire: I feel now more like Mrs. B,

19 desolued and nothing has meaning.

20 Sue: Hei, think this way. Did you

21 mistake some person before?

22 Mina: Yea, when I don't wear classes.

23 Claire: I know I know. You mean it's

24 possible for Mrs. B to see the same

25 person with different titles.

26 Mina: So, that's why the title is 'Yes,

27 Father-Sister.' father, doctor and the

28 sister are the same

29 Sue: So she is not a (fun-z). Right?

30 Mina and Claire: Yeap! conflictural

(lines 09-13)

umor

(lines11-19)

reflexivity

(lines 20-25)
Humor and

reflexivity are also

emerged in the

process of text

discussion;

however the

significance of

this discursive

example is toward

the end that they

reach the textual

understanding

with agreement.

agreement

Regarding the interview data, I first underlined the data related to the conflictual talk, and then classified these into positive and neutral positions, which were used to gauge how the participants perceived conflictual talk as a social act of reading in the process of the two text discussions.

\section{Finding and Discussion}

\subsection{How participants managed conflictual talk as a social act of reading}

In general, the conflictual talk that was generated when discussing Story One began with arguments or disagreements on what was wrong with the man, why he fell out of bed, and whether he saw his other leg or not. In contrast, when discussing Story Two, most of the groups focused on what kind of disease Mrs. B had, and why she recognized the doctor as a sister and/or father. Such conflicting talk as a process of meaning negotiation and construction brought the group members into various disputes, and thus their varied answers to questions such as why the man did not see his other leg and what disease Mrs. B had, are embedded in their social shared inquiry.

3.1.1 Collaboration

Collaboration in conflictual talk refers to participants' sharing viewpoints, providing arguments, and working toward new understandings of the texts being discussed (Author, 2012). The conversations as collaboration sparked new observations and judgments, expanding the realm of textual interpretations and experiences. Take Group 5 in Excerpt A, for example.

Excerpt A, Group 5, Story One

01 Joan: Maybe the nurse played jokes on the patient, look here-

02 Debbie: Well, I don't think this way, although it is New Year's Eve.

03 No one celebrates the New Year this way. Maybe the nurses felt upset about the patient.

04 Joan: Why?

05 Vivian: Yeah, why?

06 Debbie: Because he was very noisy, just like a baby.

07 Joan: Noisy?

08 Vivian: Do you mean he kept saying he did not see his leg?

09 Debbie: Right! But his leg was there with him.

10 Vivian: So, we all have different opinions.

11 Joan: So, is the leg there?

12 Vivian: The leg is with him; this is not the problem.

13 The problem is he did not see it but the doctor and the nurse saw it.

14 Joan: And we have agreed that he did not have mental problems.

15 Debbie: So he must have a kind of disease, making him not see his leg. 
16 Vivian, do you know?

17 Joan: Hey, this is my question. I asked her before.

18 Vivian: If he did not have mental problems, then, maybe he took some kind of medicine.

19 The medicine may make him act like this way, a funny way.

20 Or, he had some surgery, so his behaviors were changed.

21 Joan: Like brain surgery, right?

[The group switched to talk about how brain surgery may impact a patient's behaviors.]

In Excerpt A, a typical conflictual talk begins with Debbie's disagreement with Joan's idea that 'The nurse played jokes on the patient" (Line 01), and Debbie then challenges Joan's assertion using both cultural knowledge and her personal judgment (Lines 02-03). However, Debbie is further positioned by Joan and Vivian to elaborate more about her account (Lines 04-05). Debbie's elaboration (Line 06) in turn leads the group to engage in a lively discussion, allowing them to reexamine, verify, and clarify their textual understanding and interpretation, and positive disagreements thus arose in this group (Lines 11-16). Joan, the one who initiated the conversation, revised her thinking based on Vivian's and Debbie's responses to her original thoughts (Line 21). In fact, not only Joan, but also Debbie and Vivian, reformulated and re-voiced their original positions in the process of collaboration. Revoicing their positions shifted the idea from Debbie's disagreement to the group's negotiation, and from there the group could critically explore the idea without being critical of specific members. The group members in Excerpt A thus engaged in a critical and inclusive discourse move that enabled them to engage in conflictual talk as a form of collaborative shared inquiry.

3.1.2 Reflexivity

Kramsch (2010) saw the use of the reflexive self as a way of putting ourselves in other people's shoes. It is by the reflexive self that we can start remembering who we were and who we could have been and might still become, through which we can imagine the real and potential other. Neisser (1988) called this type of knowledge 'a knowing founded on memory and imagination' (p. 52). For Kramsch and Neisser (1988), the self is a social dialogic construct. Reflexivity in this article is thus defined as when a participant puts him/herself or his/her peer(s) in the story character's shoes. When participants employed reflexive positions via conflictual talk, they began to see themselves from a broader sociocultural perspective, and were able to comprehend the stories more profoundly, as shown in Excerpt B.

Excerpt B, Story 7, Story One

01. Fion: I have to say sorry because I don't quite agree. I think the patient is very touch.

02. I mean -

03. Penny: Tough?

04. Enga: Think this way. What if the doctor didn't believe what you said, how would you feel?

05. Fion: Feel frustrated.

06. Enga: See, now you understand why the patient feels frustrated.

07. Fion: I don't think the patient feels frustrated, but confused.

08. Penny: Confused about what?

09. Fion: He saw his own leg beside him but not with him, but the doctor -

10. Penny: I think if I were the patient, I would have a similar feeling.

11. Enga: What feeling?

12. Penny: It would be difficult for me to face the truth if I lost a leg. I would rather die than live.

13. My life would be miserable and inconvenient if I only had one leg to stand on.

14. Fion: So, I think he feels scared, not frustrated.

15. Enga: Scared to face the truth because he has only one leg to stand on, right?

Enga (Line 04), as shown in Excerpt B, applied reflexivity to dispute Fion's opinion (Lines 01-02) due to their opposite positions toward the story's characters, the patient and doctor. The reflexive self initiated by Enga opened another discussion dimension, leading group members to focus more on using themselves as tools to learn (Lines 0506). However, the conflictual talk continued with Fion's further challenge (Line 07), but another instance of reflexivity was also brought about by the another group member, Penny (Lines 10 and 12). Penny's responses with her reflexive self not only echoed and sustained Enga's utterances (Line 04), but also resolved their discussion's tension and the related textual ambiguities. Reflexivity in Excerpt B thus functioned as a window through which Group 8 could reexamine their previous experiences, working towards possible resolutions of contradictions between what may be desirable and what is realistic in actual practice. Participants in Excerpt B brought their reflexive selves to the text under discussion, while integrating their own voices, views and sense with those of the story's characters. In this way, the self was a means of outgrowing the participants' current selves, and the story being discussed became secondary to the discussion process. Most importantly, with the use of the reflexive self as an interpretive playground, Enga and Fion in Excerpt B began with disagreements but ended with mutual understanding and consensus, making the exchange more like a collaborative dialogue (Lines 13 and 14). The conflictual talk that emerged with reflexivity in Excerpt $\mathrm{B}$ made an important and unique contribution to helping the members of this group to learn more from each other. 


\subsubsection{Humor}

There were numerous examples of small-group discussions that might simply be seen as conversations that had little to do with the texts and discussion tasks that the participants were engaged in. In fact, many such exchanges did originate from the task itself. In the following excerpt, Bob's sense of humor functioned somewhat like tangential talk linking both the talk and the text, but his sense of humor had a positive effect on the group interactions.

Excerpt C, Group 7, Story Two

01 Tina: I don't think she is crazy. She is all right to me.

02 She just had different opinions about people, like-

03 Ruby: How can you see a person as a father and as a sister?

04 Tina: Well, when you are a child, M means McDonald.

05 When you grow up, M does not mean anything, just M. Right, Bob?

06 Bob: M means M \& M to me. [Tina and Ruby laugh.] So, you [to Tina] mean

07 Mrs. B had no mental problems. She just saw things differently from the doctor and the nurses, 08 just like the adult and the child saw "M" as having different meanings.

09 Ruby: I know, I know. Mmm... We always see things with different eyes.

As indicated in Excerpt C, because of Bob's humor (Line 06), Tina and Ruby were freed from the argument they were engaged in. Tina used the McDonald's sign to explain why Mrs. B could not tell the difference between a father and a sister (Line 03), and Bob shared his personal experience with a joke, but he soon brought himself back to the discussion of the text. As a listener, Bob perceived and understood Tina's utterances with addressive and responsive statements, functioning as support to relieve the group tensions. Bob's humor not only made Tina and Ruby laugh and feel good, but also established a positive environment where learning was enhanced and rapport built up. In fact, Bob's joke served multiple functions to help achieve the group's communicative goals. On the surface level, his joke bridged the discussion gaps between Ruby and Tina; on a more profound level, Bob reframed and reformulated Tina's utterances (Lines 01-02) with a re-contextualized version of his own. Most importantly, Bob's performance with appropriations enabled and encouraged Ruby to understand Tina's thoughts as to why Mrs. B could not see the doctor as a whole person (Line 05). That is, Bob successfully appropriated the knowledge and discourse of the text and the talk being discussed via his responsive appropriations, making it possible to present an idea of his own. Bob's utterances (Line 04) echoed Bakhtin's “double- voiced” discourse (1981, p.65), filled with Tina's words but fitting Bob's own communicative purposes.

\subsubsection{Alteration}

Not every moment of conflictual talk is productive and thought-provoking, and not all participants can immediately embrace conflict, as shown in Extracts A-C. Instead, conflictual talk has its challenging moments when ambiguities prevail and difficulties mount. In order to manage such situations, another exchange strategy was quite frequently utilized, a change of the discussion topic to avoid group confrontations. As shown in Excerpt D, below, topic alteration was on the one hand a way to run away from confrontations, but on the other it also ensured that group communication and text discussion continued.

Extract D, Group 3, Story Two

01 May: She got crazy, I mean -

02 Lynn: I didn't think Mrs. B got crazy. She just got a disease.

03. May: If not, why did she not recognize the doctor, sister, father.

04 Nothing means anything. She feels depressed and she had mental problems.

05 Lynn: I think she is a "de-souled.'

06 May: De-souled? No soul? Like a ghost? -

07 Jean: Maybe we should talk more about how she can not have the feeling and meaning,

08 not circle around why she can't recognize the doctor, father, sister as a whole person.

10 Lynn: Okay, I agree.

11 May: Fine with me.

Instead of being mired in further arguments, the participants in Excerpt D stumbled over the dispute for a while, then quickly switched to a new topic and adopted diverse perspectives toward the story under discussion. For Jean, although she may not have been astute enough to switch discussion topics intentionally, generating a new discussion direction (Line 07), such a switch did relieve the group tension arising from arguments. More importantly, a change of discussion direction may simultaneously extend participants' meaning negotiation and construction, and thus the text discussion could continue smoothly. In fact, like Jean's situation in Excerpt D, alteration functioned as a useful strategy utilized by other group members, giving the participants the resources needed to adapt, persevere, and regain their selfcontrol following tension. Most importantly, the topic alteration suggested by Jean needed support from her peers. Therefore, with both Lynn's (Line 06) and May's (Line 07) recognition and acknowledgement, the topic alteration helped the group members to stretch the boundaries of their knowledge and discourse. Shielding participants from this tension shielded them not only from discussing the content under discussion, but also from processes that could lead to greater textual understanding. Such confrontations may thus result in poor quality text discussions, as shown in Excerpt E. 


\subsubsection{Collision}

Conflictual talk provided multiple opportunities for most of the groups to carry out meaning negotiation and construction in the process of text discussions, but it was not always as positive and smooth as shown in Excerpts A-C. In fact, disputes generated from conflictual talk sometimes continued, no matter how hard the participants tried to manage the difficulties they encountered. The interrelationships among the group members thus become strained and aversive. Indeed, at this moment some participants felt impatient or apprehensive (interview data). Disagreements and arguments existed among the group members, so conflicting talk surfaced and gradually intensified, leading to conflict, sometimes even blocking any further inclination to talk, as shown in Extract E, and the tense relationships among the group members closed off opportunities for learning and exploration.

Excerpt E, Group 6, Story Two

01.Joy: I'm confused. You [to Suie] don't agree she is sick and you also don't agree she is normal.

02 So, what's your point?

03 Suie: I don't think she is sick. I just feel something wrong with her.

04 A person with funny behaviors doesn't mean she is crazy or ill.

05 Joy: Then, tell me what's wrong with Mrs. B?

06 Amy: Yeah, what's wrong with her?

07 Suie: She can't recognize a whole person, and this does not mean -

08 Amy: But you have said this before, but did not tell us why

09 she can't recognize the doctor as a whole person.

10 Joy: I am confused, very confused with your ideas, Suie.

11 Amy: Me, too. Listen, Suie. -

[Instead of listening, Suie continued to talk, dancing around the idea that Mrs. B can't recognize the doctor again. Joy and Amy kept silent for a while, without any responses.]

Example F, Suie's interview data

Amy and Joy keep asking me to explain more, but I don't know how. ...Their pushes made me feel nervous, so I could only repeat my ideas. My English is not good enough to express my ideas freely....

The conflictual talk in Excerpt E started with Joy's re-voicing Suie's dual points (Lines 01-02). However, Suie's responses (Line 03) did not meet Joy's and Amy's expectations and her reasoning was not clear, and thus the arguments in this group continued, and even became more intense. The problem in this example lay in Suie's ignorance with regard to her peers' suggestions (Lines 08-11) when encountering textual incomprehensibility and ambiguities. Consequently, her peers, Joy and Amy, were forced to give up their floors and turn-takings, and so the opportunities for group verbal interactions were reduced or even eliminated. In fact, Joy and Amy in Excerpt E did not know how to handle disputes, and thus ultimately they refused to talk (interview data). Joy's and Amy's disengagement in Excerpt E thus functioned as a form of response that was an act of resistance, and they passively removed themselves from the scene of confrontation while remaining in a marginal social position. On the other hand, Suie's responses in Excerpt F reveal that she was under double pressures, due to these conflicts and her inadequate English proficiency.

\subsubsection{Discussion}

The conflictual talk found in this study emerged from the ambiguities, incomprehensibilities, misunderstandings, and even absurdities that arose in the process of text discussions, often creating group tension. Accommodation to such tension is not a smooth process, but one which, in its essence, relies on how group members deal with the situation they are facing. Reciprocity is the crux of conflictual talk, and with recognition, acknowledgement and mutual support among peers, collaborative shared inquiry is able to occur, as seen in Excerpts A-C. The talk within a supportive environment opened up a broader range of connections among the members themselves, and in turn facilitated their greater understanding of the texts being discussed. The collaboration and reflexivity seen in Excerpts A-B did not occur naturally, and instead the participants' desire to take a part in the group discussion was a key element in the process. This desire relied on the atmosphere within each group, since the each member's words, ideas, and experiences were heard, heeded, and responded to within a supportive environment. In fact, how the group members engaged in conflictual talk about a text can also reveal leadership in small-group discussions. For example, Vivian in Excerpt A was the group member with greater knowledge of English, and thus her peers turned to her for information and explanations when encountering difficulties (Lines 13-14). Vivian was also interested in assuming authority, and thus was happy to go along with her group's expectations (Turns 11 and 15). On the other hand, for collaborative shared inquiry to occur, as shown in Extracts B-C, it is not so much a more capable or knowledgeable other that is required, but a willingness on the part of the group members to eagerly learn with and from each other. Power in these groups was thus created by peers rather than being imposed on or exercised over group members.

Furthermore, as shown in Excerpts A-B, the group members were willing to conclude the disagreements without resolution, which was indicative of their willingness to grapple with the uncertainty of text discussions. In this sense, social shared inquiry via collaboration and reflexivity is viewed as a means for these participants to appreciate both the texts and their peers' views, and such appreciation may help them redefine aspects of themselves through contrast with the opposite aspects in a fictional other which they have temporarily experienced in moments of confusion. Bob's socially situated talk in Excerpt $\mathrm{C}$ reveals that the internally persuasive words that arise during conflicts are not static 
and isolated, but rather a part of a creative process that can be reproducible in and applied to new situations. Indeed, humor, joking, or even teasing among group members were quite frequently seen in conflictual talk, functioning as one of the most useful ways, if not the best way, to alleviate the negative aspects of group discussions, for such situations cannot be understood by merely commenting on the substance of the text discussions, but should be viewed as creating and safeguarding the bonds of mutual concern, trust, respect, and appreciation that are crucial to the preservation of a group's relationships. Another strategy used to alleviate group tension was topic alteration. As presented in Excerpt D, topic alteration, like a sedative, relieved the temporary tension that arose in conflictual talk, but may not have enhanced textual understanding if the group simply used it as a rejection tactic without adopting any critical stances, or else simply shied away from disagreements. Under these circumstances, the tense atmosphere among members could be temporarily relieved, but social conflict may have been generated by some members' dissatisfaction with or apprehension toward the discussion behaviors. Much worse, if the group members, like Suie in Excerpt E, simply danced around or stumbled over the parts that they were puzzled about, clashes in the discussion were likely to have hindered further conversations. For meaningful text discussions to occur in small group work, it is essential to allow the participants to generate alternative views and responses to express their understandings, interests, and preferences, but, equally important, group members are also required to listen carefully to one another. The collision in Extract E reveals that attentive listening as a form of supporting exchange could serve as both a response and a way to build rapport.

\subsection{How Participant Perceived Conflictual Talk as a Social Act of Reading}

In response to how participants perceived conflictual talk as social act of reading, 26 out of 30 participants positively viewed conflictual talk as shared inquiry process in which the group members positioned and were positioned to engage in talking, arguing, debating, re-thinking, and re-valuing. As a result, not only were they encouraged to express opinions and challenge each other's perspectives, but they were also provided with continued opportunities to learn more about the texts and their changing perspectives, as indicated below.

Excerpt G, Debbie's response

In the beginning, we felt confused and didn't know how to discuss; in the middle of talking, we argued and laughed. In the end, we were still confused, argued with each other, but we like the story more. 'Yes, FatherSister,' is fun to discuss, since we have many free associations. When we discussed 'Yes, Father-Sister,' we had a lot of arguments and had a lot of fun, too. It was a great feeling.

Excerpt H, Mina's response

...Our arguments helped me clarify many confusing points, especially Lynn. She always gave different ideas, even opposing opinions, challenging us to think with different angles. She is just as intelligent as Mrs. B. ...

Excerpt I, Fay's response

...We decided not take any arguments or disagreements too seriously. We think we should have different ideas and that's what the small-group discussion is for.... I learned many things from our arguments. I like Victoria's thoughts, insightful and interesting. I also like Sandy's funny jokes, since she made us feel relaxed.

Like Debbie and Mina in Excerpts G-H, some participants not only valued their peers as helpful resources in the discussion process, but also perceived the conflictual talk as "free and associative" (Penny's interview), providing a "more compelling impetus for them to carry on the discussion" (Jean's interview). That is, conflictual talk was viewed as an inquiry process, one in which the participants aim to seek alternative ways of talking about the text, thus struggling in and out of chaos. On the other hand, as indicated in Excerpt I, Fay's group members succeeded in locating common ground within the group itself, so that their opposing positions, disagreements, or even arguments appeared as means of mutual communication and negotiation. They were thus able to initially establish some basis for solidarity through shared purposes and experiences. In fact, the key to establishing group solidarity, as well as moving the group forward, was their mutual communication, as continue talk kept the whole group immersed in creating a foundation for openness, trust, and receptivity. However, for various reasons a few participants took a neutral or even a negative view of conflictual talk, as seen in the following two examples (Excerpts J-K).

Excerpt J, Amy's interview

While discussing "Yes, Father, ...." the second story, I lost my reading direction and my group did not know how to discuss it. We always wandered around some ideas again and again; sometimes I felt we just wasted time.

Excerpt K, Linda's interview

... But sometimes we just argued and argued, and danced around the topics and didn't know how to continue. In fact, I had many questions after our small-group discussion. I wished we could have chances to listen to other groups' ideas. It would be interesting and helpful.

Actually, negative attitudes toward conflictual talk, as stated in Excerpts J-K, were due to their lack of resources with regard to resolving their conflictual talk, the small-group text discussions become more difficult. These factors then led to disruption, rather than greater peer communication.

\section{Conclusion}

This study explored how 10 groups of Taiwanese university students managed conflictual talk via collaboration, reflectivity, humor, alteration and collision in the process of small-group text discussions. In line with the findings in 
Almasi's (1995), Almasi and Gambrell's (1997) and Author's (2012), group members in Excerpts A-D demonstrated that the potential benefits of conflictual talk in small-group text discussions depend upon the group members' willingness to consider the ideas and opinions of others' in the following situations: when members were able to consider alternative interpretations; when they were willing to be changed; when there was no strong emotional or defensive involvement in a character, situation, or event; and when peer responses were not impermeable. Such conversations sparked new observations and judgments, expanding the realm of textual interpretations and experiences. In this sense, conflictual talk engaged participants in the construction of knowledge and of language, advanced their learning, and provided opportunities for them to learn more and inquire further while conversing, interpreting, and negotiating in active and constructive ways.

In their interview responses, most participants' attitudes toward conflictural talk were positive as a way to promote their reading comprehension and textual interpretation, but the reasons underlying their perceptions were rather varied. Conflictual talk was used as a way of fostering conversation and negotiation, functioning as a shared inquiry in which the participants' textual experiences were enhanced and broadened, which then promoted their reading comprehension and textual interpretation.

While many teachers have focused on how to gauge language learning by paying close attention to verbal participation, few knew how to attend to listening as a form of participation. Future studies are thus needed to examine the complex role that listening plays in small-group text discussions. That is, students' oral participation needs to be redefined to include multimodal responses and engagement in listening. Future research thus needs to explore how listening, like speaking, can carry multiple meanings, such as collaboration, reflexivity, humor and alternation, as presented in this article. Conflictual talk as a form of social, shared inquiry can only occur within a community of co-learners that is composed of speakers and listeners, participants and peers.

As with all qualitative research, the five aspects generated from the conflictual talk presented in this article must be investigated in future studies conducted with the participation of larger numbers of students in more varied linguistic levels and cultural backgrounds. Moreover, educators need to explore when students are able to manage conflictual talk better, and in what ways such management informs their further inquiry, and whether this talk could also mirror reading as social, shared inquiry, as well as promote textual interpretations and even facilitate group cooperation.

\section{References}

Almasi, J. F. (1995). The nature of fourth graders' sociocognitive conflicts in peer-led and teacher-led discussion of literature. Reading Research Quarterly, 30(5), 314-351.

Almasi, J. F. \& Gambrell, L.B (1997). Conflict during classroom discussions can be a good thing. In J. R. Paratore \& R. L. M.cCormack (Eds.), Peer talk in the Classroom learning from research (pp. 130-155). Newark, Delaware: International Reading Association.

Bakhtin, M. M. (1981). The dialogic imagination. Austin: TX: University of Texas.

Berne, J. I., \& Clark, K. F. (2006). Comprehension strategy use during peer-led discussions of text: Ninth-graders tackle “The Lottery." Journal of Adolescent \& Adult Literacy, 49(8), 674-686. DOI: 10.1598/JAAL.49.8.4

Bloome, D., Carter, S. P., Christian, B. M., Madrid, S., Otto, S., Shuart-Faris., N., \& Smith, M. (2008). Discourse analysis in classrooms: Approaches to language and literacy research. New York, NY: Teachers College Press.

Carson, J.G., \& Nelson, G. L. (1994). Writing groups: Cross-cultural issues. Journal of Second Language Writing, 3 , 17-30.

Carson, J. G., \& Nelson, G. L. (1996). Chinese students' perceptions of ESL peer response group interaction. Journal of Second Language Writing, 5, 1-20.

Chi, F.-m. (2012). Searching for intertextual connections in small group text discussion. Journal of Research in Reading, 35(3), 251-266.

Corbin, J. \& Strauss, A. C. (2008). Basics of qualitative research: Techniques and procedures for developing grounded theory ( $3^{\text {rd }}$ ed.). Los Angles: Sage.

Kramsch. C. (2010). The multilingual subject. New York: Oxford University Press.

McElvain, C. M. (2010). Transactional literature circles and the reading comprehension of English learners in the mainstream classroom. Journal of Research in Reading, 33(2), 178-205. DOI: 10.1111/j.1467-9817.2009.01403.x

Neisser, U. (1988). Five kinds of knowledge. Philosophical Psychology, 1(1), 35-59.

Purky, J. (2008). Inviting conversation: meaningful talk about texts for English language learners. Literacy, $42,44-51$. DOI:10.1111/j.1467-9345.2008.00479.x

Sacks, O. (1985). The man who mistook his wife for a hat and other clinical tales. N.Y.: Harper Perennial.

Short, K., \& Burke, C. (1996). Creating classrooms for authors and inquirers. Portsmouth, NH: Heinemann. van Manen, M. (1990). Researching lived experience: Human science for an action sensitive pedagogy. New York: State University of New York Press.

Wells, G. (1999). Dialogical inquiry: Towards a sociocultural practice and theory of education. New York: Cambridge University Press. 
Wray, D., \& Lewis, M. (1996). "But bonsai trees don’t grow in baskets": Young children's talk during authentic inquiries. In L. B. Gambrell \& J. F. Almasi (Eds.), Lively discussions! Fostering engaged reading (pp. 63-72). Newark, DE: International Reading Associations.

Appendix: Transcription Keys

\begin{tabular}{|c|c|}
\hline Symbols & Meanings \\
\hline- & Interruption. \\
\hline$\cdots$ & $\begin{array}{l}\text { Short hesitation. One period marks a perceptible pause. Thereafter, each period } \\
\text { corresponds to two seconds of pause, e.g., "Mmm,...All right." }\end{array}$ \\
\hline [ ] & $\begin{array}{l}\text { Square brackets enclose descriptions of the relevant non-verbal behaviors or } \\
\text { interpretation by the researcher from video or audio taping. }\end{array}$ \\
\hline\{\}() & Romanization of Mandarin along with the English translation. \\
\hline “” & Words that are directly quoted from story are enclosed in inverted commas. \\
\hline
\end{tabular}

